\title{
The Effects of Harmonic Components on Transformer Losses of Sinusoidal Source Supplying Non-Linear Loads
}

\author{
I. Daut, H.S. Syafruddin, Rosnazri Ali, M. Samila and H. Haziah \\ School of Electrical System Engineering, Kolej Universiti Kejuruteraan Utara Malaysia (KUKUM) \\ 02600 Jejawi, Perlis, Malaysia
}

\begin{abstract}
An important consideration when evaluating the impact of harmonics is their effect on power system component and loads. Transformers are major components in power systems. The increased losses due to harmonic distortion can cause excessive losses and hence abnormal temperature rise. The measurement of iron losses and copper losses of single-phase transformers is important in particular for transformers feeding nonlinear loads. In computing of transformer losses, it is assumed that source voltage is sinusoidal and load impedance is linear. This study presents the effects of harmonic distortion of load current and voltage on single-phase transformer losses utilizing the on-line measurements (monitoring) method of the primary side. The transformer is loaded with an SCR speed controller that consists of a single-phase full-bridge rectifier, SCR and a resistant load to generate various total harmonic current and voltage distortions (THDi and THDv) conditions.
\end{abstract}

Key words: Harmonic, sinusoidal source, nonlinear load, total harmonic distortion (THD)

\section{INTRODUCTION}

The usage of nonlinear loads on power systems increasingly creates the awareness of the potential reduction of a transformer's operational life due to increase heat losses. The performance analysis of transformers in harmonic environment requires knowledge of the load mix, details of the load current harmonic content and total harmonic distortion (THD). The additional heating experienced by a transformer depends on the harmonic content of the load current and the design principles of the transformer ${ }^{[1]}$.

The harmonic problems are mainly due to the substantial increase of nonlinear loads due to technological advances, such as the use of power electronic circuits and devices, in ac/dc transmission links, or loads in the control of power systems using power electronic or microprocessor controllers. In general, sources of harmonics are divided into : (a) Domestic loads, (b) Industrial loads and (c) Control devices $^{[2]}$.

Increases in harmonic distortion component of a transformer will result in additional heating losses, shorter insulation lifetime, higher temperature and insulation stress, reduced power factor, lower productivity, efficiency, capacity and lack of system performance of the plant ${ }^{[3]}$.

Harmonic load content estimation methods: There are three methods of estimating harmonic load content: the Crest-factor (CF), Harmonic Factor or percentage of Total Harmonic Distortion (\%THD) and "K-Factor". In this study we will focus on two methods; those are CF and \%THD. The very simple harmonic estimation technique is the Crest Factor. Crest Factor is a measure of the peak value of the waveform compared to the true RMS value. The mathematical definition, of the crest factor is the ratio of the peak value of the waveform divided by the rms value of the waveform:

$$
\mathrm{CF}=\frac{\text { Peak of waveform }}{\text { rms of waveform }}
$$
voltage will have a crest factor of $\sqrt{2}$ or 1.414 and any deviation of this value represents a distorted waveform $^{[4]}$.

The percentage of total harmonic distortion (\%THD) can be defined in two different ways, as a percentage of the fundamental component (the IEEE definition of THD) or as a percentage of the rms (used by the Canadian Standards Association and the IEC) ${ }^{[5]}$. The later standard is referred in this study.

$\mathrm{THD}=\frac{\sqrt{\sum_{\mathrm{h}=2}^{\infty} \mathrm{V}_{\mathrm{h}, \mathrm{rms}}^{2}}}{\mathrm{~V}_{\mathrm{rms}}} \times 100 \%$

where $\mathrm{V}_{\mathrm{h}, \mathrm{rms}}$ is the amplitude of the harmonic component of order $\mathrm{h}$ (i.e., the $h$ th harmonic) and $\mathrm{V}_{\mathrm{rms}}$ is the rms values of all the harmonics) that can be represented as

$\mathrm{V}_{\mathrm{rms}}=\sqrt{\sum_{\mathrm{h}=1}^{\infty} \mathrm{V}_{\mathrm{h}, \mathrm{rms}}^{2}}$

Corresponding Author: Syafruddin Hasan, School of Electrical System Engineering, Kolej Universiti Kejuruteraan Utara, Malaysia, 02600 Jejawi, Perlis, Malaysia, Tel: +604-9798146, Fax: +604-9798304 
Am. J. Applied Sci., 3 (12): 2131-2133, 2006

Table 1: Experimental results

\begin{tabular}{llllllllll}
\hline $\mathrm{V}_{\text {in }}(\mathrm{V})$ & $\mathrm{I}_{\mathrm{i}} \mathrm{pk}(\mathrm{A})$ & $\mathrm{I}_{\mathrm{i}}$ fund $(\mathrm{A})$ & $\mathrm{I}_{\mathrm{i}} \mathrm{rms}(\mathrm{A})$ & $\mathrm{P}(\mathrm{W})$ & $\mathrm{CF}$ & $\% \mathrm{THD}$ & $\mathrm{PF}$ & $\mathrm{V}_{\text {out }}(\mathrm{V})$ & $\mathrm{I}_{\text {out }}(\mathrm{A})$ \\
\hline 75 & 0.125 & 0.050 & 0.060 & 3.6 & 2.083 & 21.32 & 0.816 & 15 & 0.05 \\
100 & 0.172 & 0.085 & 0.100 & 7.3 & 1.720 & 57.88 & 0.864 & 28 & 0.10 \\
125 & 0.192 & 0.112 & 0.125 & 12.5 & 1.536 & 60.05 & 0.809 & 36 & 0.14 \\
150 & 0.225 & 0.133 & 0.143 & 18.9 & 1.573 & 46.16 & 0.883 & 48 & 0.18 \\
175 & 0.258 & 0.160 & 0.170 & 28.4 & 1.518 & 10.99 & 0.954 & 63 & 0.22 \\
200 & 0.293 & 0.188 & 0.198 & 37.5 & 1.480 & 10.56 & 0.949 & 79 & 0.26 \\
230 & 0.334 & 0.226 & 0.236 & 50.7 & 1.415 & 19.92 & 0.934 & 90 & 0.30 \\
\hline
\end{tabular}

The total power factor is called distortion power and results from the harmonic component of the current:

$\mathrm{PF}=\frac{1}{\sqrt{1+\mathrm{THD}^{2}}}$. DPF

where DPF is the displacement power factor, assuming that for non-inductive or non-capacitive loads, the value can be considered as 1 .

Experimental set-up: The arrangement of equipment set-up is as shown in Fig. 1. The experiment was conducted by varying the input voltage but constantly maintained the SCR trigger angle and load resistance value.

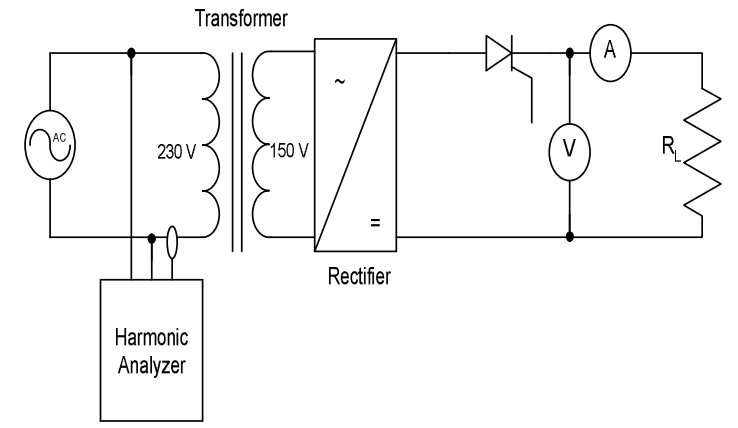

Fig. 1: Arrangement of experimental set-up

\section{RESULT AND DISCUSSION}

The experimental results are as shown in Table 1. The related current and voltage waveforms and the respective harmonic distribution for the two input or primary voltages $(75 \mathrm{~V}$ and $200 \mathrm{~V}$ ) are depicted as shown in Fig. 2 and 3.

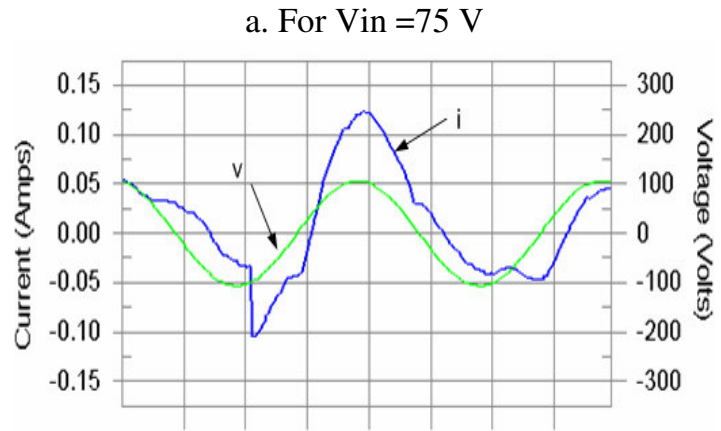

Fig. 2: Current and Voltage waveforms for input voltage of $75 \mathrm{~V}$

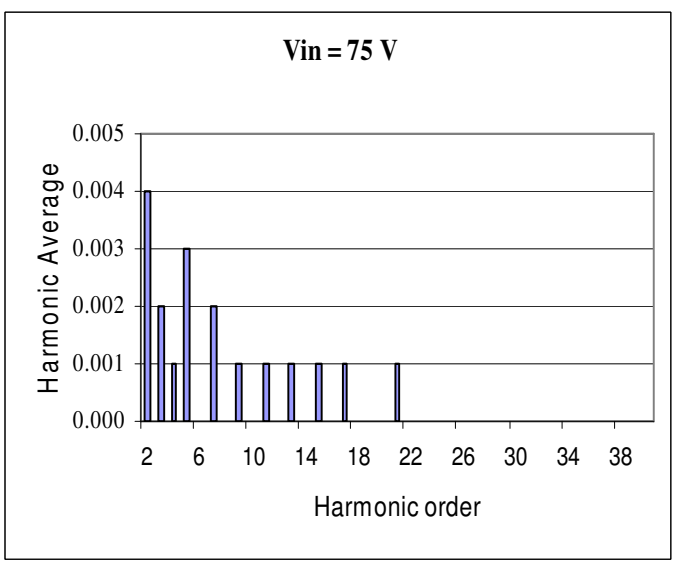

a. Harmonic distribution of input current for Vin $=75 \mathrm{~V}$

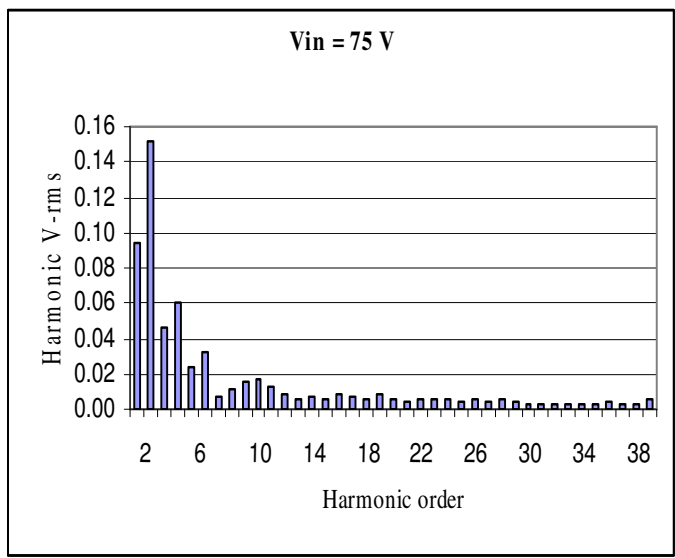

b. Harmonic distribution of input voltage for Vin $=75 \mathrm{~V}$

\section{b. For Vin $=200 \mathrm{~V}$}

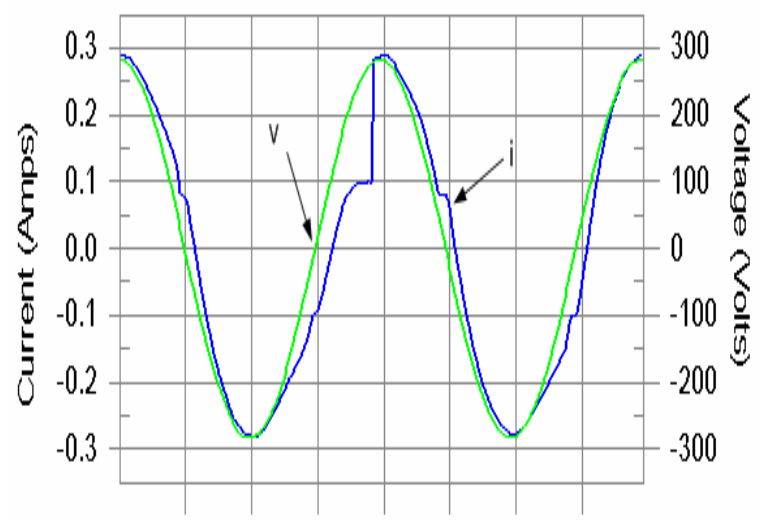

Fig. 3: Current and Voltage waveform for input voltage of $200 \mathrm{~V}$ 


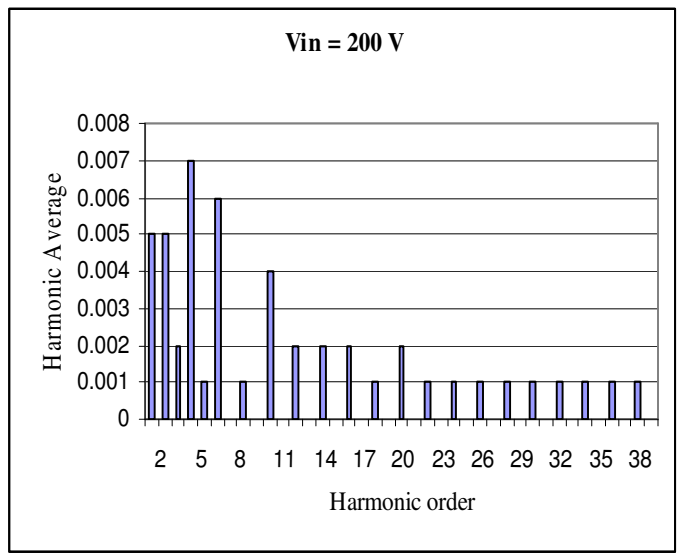

a. Harmonic distribution of input current for Vin=200V

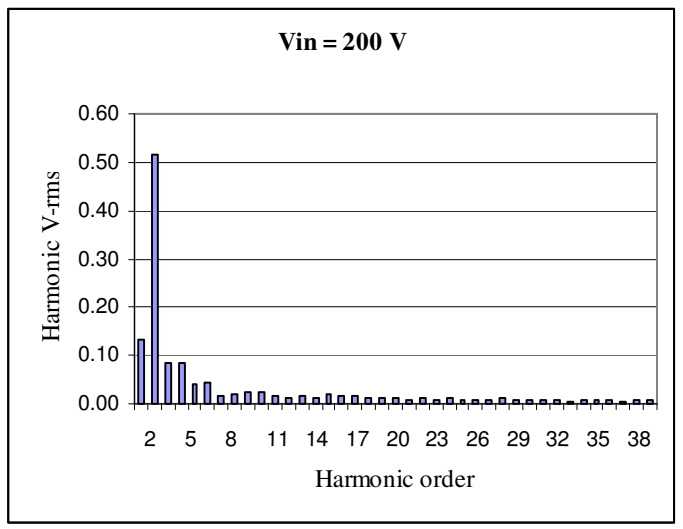

b. Harmonic distribution of input voltage for Vin $=200 \mathrm{~V}$

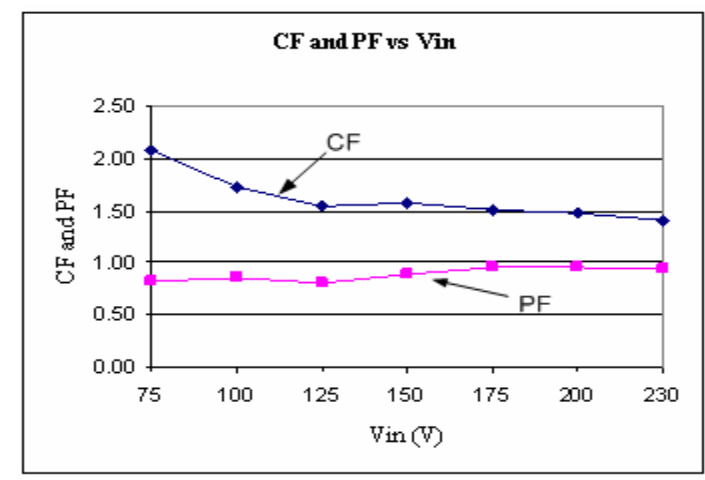

Fig. 4: Variations of $\mathrm{CF}$ and $\mathrm{PF}$ due to change of input voltage
The variation of crest factor CF and it's power factor PF due to the variation of input voltage that was supplied to the primary side of transformer is shown in Fig. 4.

\section{CONCLUSION}

In this study, the operation of a single phase transformer is considered for sinusoidal power source and nonlinear load only.

From experimental results, it is observed that input power factor is significantly dependent on the harmonic content of the system. The power factor decreases with the increasing of total harmonic distortion. The total harmonic distortion and crest factor are higher at low input voltage compared to higher input voltage. These conditions are represented clearly by current and voltage waveforms in Fig. 2 and 3. As a conclusion, the transformer is not recommended to operate at lower than its rated voltage.

\section{REFERENCES}

1. Jayasinghe, R.N. et al., 2003. Power system harmonic effects on distribution transformers and new design considerations for $\mathrm{K}$ factor transformers. IEE Sri Lanka Annual Sessions.

2. Maswood, I.A. et al., 2002. Harmonics, sources, effects and mitigation techniques. Second Intl. Conf. on Electrical and Computer Engineering, ICECE 2002, Dhaka, Bangladeh, pp: 26-28.

3. Salih, T.M. et al., 2000. The Effect of the harmonic components upon transformer active losses in case of (non) sinusoidal sources and (non) linear loads. Department of Electrical Engineering Yildiz Technical University, Istambul, Turkey.

4. Gregory, M.W., 1994. Estimation methods for power system harmonic effects on power distribution transformers. IEEE Trans. Industry Appl., 30: 2.

5. Skvarenina, L.T. and D.E. William, 2004. Electrical Power and Controls. $2^{\text {nd }}$ Edn. Pearson Prentice Hall, New Jersey. 